\title{
Hydro-Thermal Scheduling: Using Soft Computing Technique Approch
}

\author{
Sudipta Sen, Arka Roy \\ (ELECTRICAL ENGINEERING / Techno India, India) \\ (ELECTRICAL ENGINEERING / Techno India, India)
}

\begin{abstract}
The project work HYDRO-THERMAL SCHEDULING is done to optimize generation cost of power in a hydro-thermal power plant using MATLAB software. This is basically a simulation project. Here three different types of techniques or algorithms have been used. These are classical method of solving short term fixed head hydrothermal scheduling, Genetic algorithm and Differential Evolution method. Genetic algorithm is a meta-heuristic search method and Differential Evolution is another method which makes the results better by generation to generation. Here the results of all these algorithms and methods are compared and the best result is obtained to optimize the cost function.

For performing the comparative study among the three methods the help of the software MATLAB has been taken as a tool for coding. This study is being performed on a primitive hydro-thermal power system network consisting of one thermal power plant and one hydel power plant. Genetic algorithm has emerged as a candidate due to its flexibility and efficiency for many optimization applications. DE or differential evolution belongs to the class of evolutionary algorithms that include evolution strategies (ES) and conventional genetic algorithms $(G A)$.
\end{abstract}

Keywords - [1] Classical Method [2] Differential Evolution [3] Generic Algorithm [ 4] Hydro-Thermal Scheduling [5]MATLAB

\section{Introduction}

A modern power system consists of a large number of thermal and hydel power plants connected at various load centers through a transmission network. An important objective in the operation of such a power system is to generate and transmit power to meet the system load demand at minimum fuel cost by an optimal mix of various types of plants. The study of the problem of optimal scheduling of power generation at various plants in a power system is of paramount importance, particularly where the hydel sources are scarce and high cost of thermal generation has to be relied upon to meet the power demand. The hydel resources being extremely limited, the worth water is greatly increased. If optimum use is made of their limited resources in conjunction with the thermal sources, huge saving in fuel and the associated cost can be made.

In certain sectors, however, the hydel source is sufficiently large, particularly in rainy seasons as the inflows into the hydel exhibit an annual cyclicity. Moreover there may be a seasonal variation in power demand on the system, and this too exhibits an annual cyclicity. The optimization interval of one year is thus a natural choice for long range optimal generation scheduling. The solution to the scheduling problem in this case consists of determination of water quantities to be drawn from the reservoirs for hydel generation in each subinterval and the corresponding thermal generation to meet the load demand over each sub-interval utilizing the entire quantity of water available for power generation during the total interval. The long range scheduling (generally persisting from months to year) involves mainly the scheduling of water release. Long range scheduling also involves meteorological and statistical analysis. The benefit of this scheduling is to save the cost of generation, in addition to meeting the agricultural and irrigational requirements. Long range scheduling involves optimization of the operating policy in the context of major unknowns such as load, hydroelectric inflows, unit availability etc.

The short range problem usually has an optimization interval of a day or a week. This period is normally divided into sub-intervals for scheduled purposes. Here the load, water inflows and unit availability are assumed to be known. A set of starting conditions being given, an optimal hourly schedule can be prepared that minimizes a desired objective while meeting system constraints successfully.

Cost optimization of hydro stations can be achieved by assuming the water head constant and converting the incremental water rate characteristics to incremental fuel cost curve by multiplying it with the cost of water per cubic meter and applying the conventional technique of minimizing the cost function. 


\section{Problem Definition}

Short term fixed head hydro-thermal scheduling considering transmission line loss and involving multiple thermal and hydro generators for minimizing thermal generation cost and optimal use of limited water resource available.

The endeavor of this project is to perform a comparative study of the results obtained by solving the hydro-thermal scheduling problem with the help the Classical method, the Genetic Algorithm and the Differential Evolutionary Algorithm and draw a conclusion about their effectivity in solving this optimization problem.

A hydro thermal system consists of one thermal and one hydro unit. The units have following characteristics.

Hydro plant: $\quad \mathrm{W}=\left(0.2 p_{h}^{2}+2.5 p_{h}+1.5 * 10^{4}\right) \mathrm{m}^{3} / \mathrm{hr}$

Volume of water available $=42 * 10^{4} \mathrm{~m}^{3}$

Thermal plant : $F_{c}=\left(0.002 p_{t h}^{2}+10 p_{t h}+1000\right)$ unit of cost/MW

Prepare a hydrothermal schedule per hour basis for the same plant for one day, where the load has the following schedule:

12 midnight-12 noon :350 MW, 12 noon-12 midnight:700 MW

Consider $\epsilon_{1}=0.001$ and $\epsilon_{2}=0.001$

The B-coefficient matrix of the system is

$\left[\begin{array}{ll}B_{11} & B_{12} \\ B_{21} & B_{22}\end{array}\right]=\left[\begin{array}{cc}0.45 & -0.05 \\ -0.05 & 4.45\end{array}\right] * 10^{-5}$

\section{Planning and Approach}

For performing the comparative study among the three methods the help of the software MATLAB has been taken as a tool for coding. This study is being performed on a primitive hydro-thermal power system network consisting of one thermal power plant and one hydel power plant.

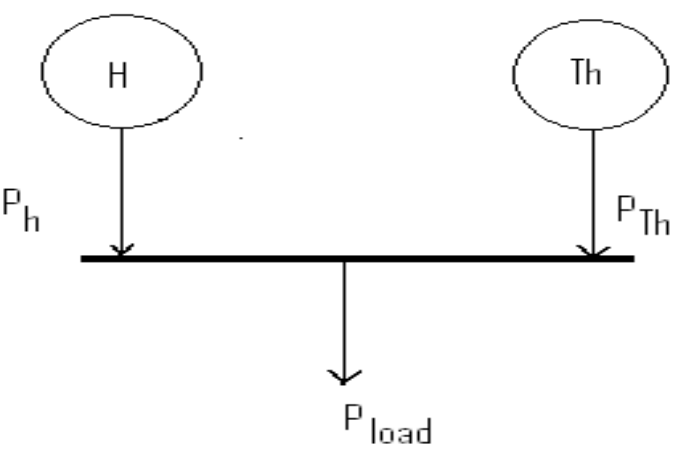

Fig 1 


\subsection{Classical Method}

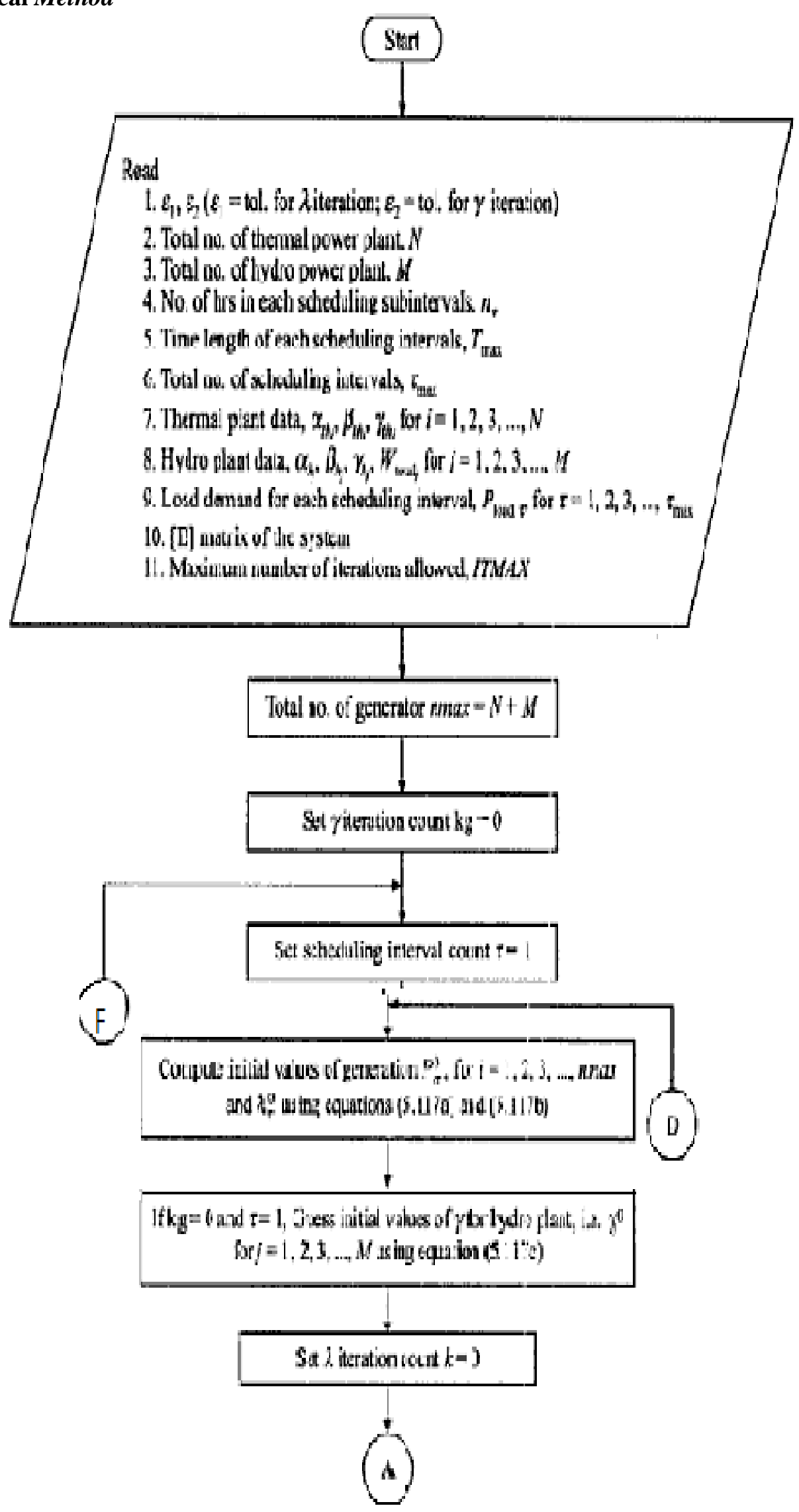




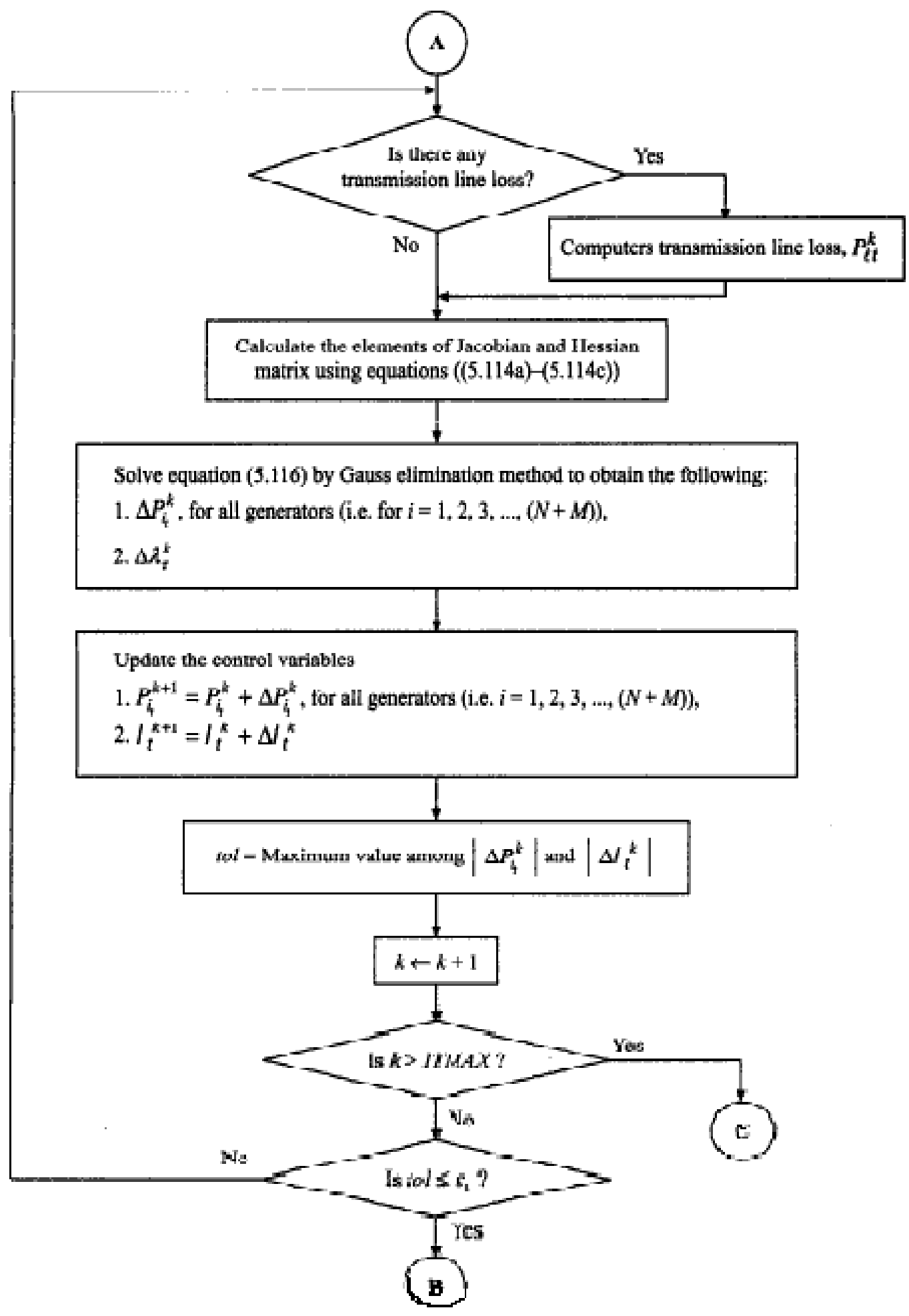




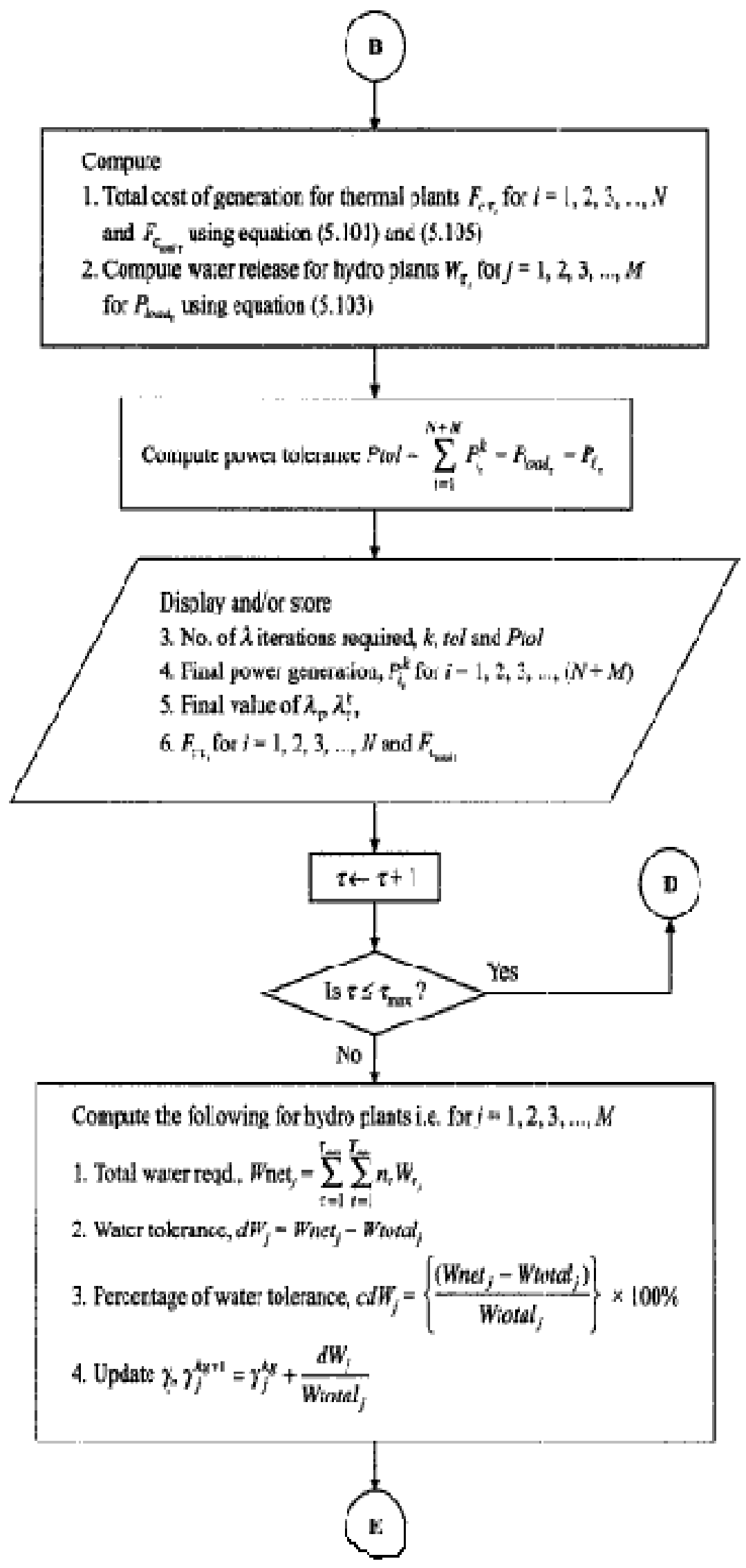




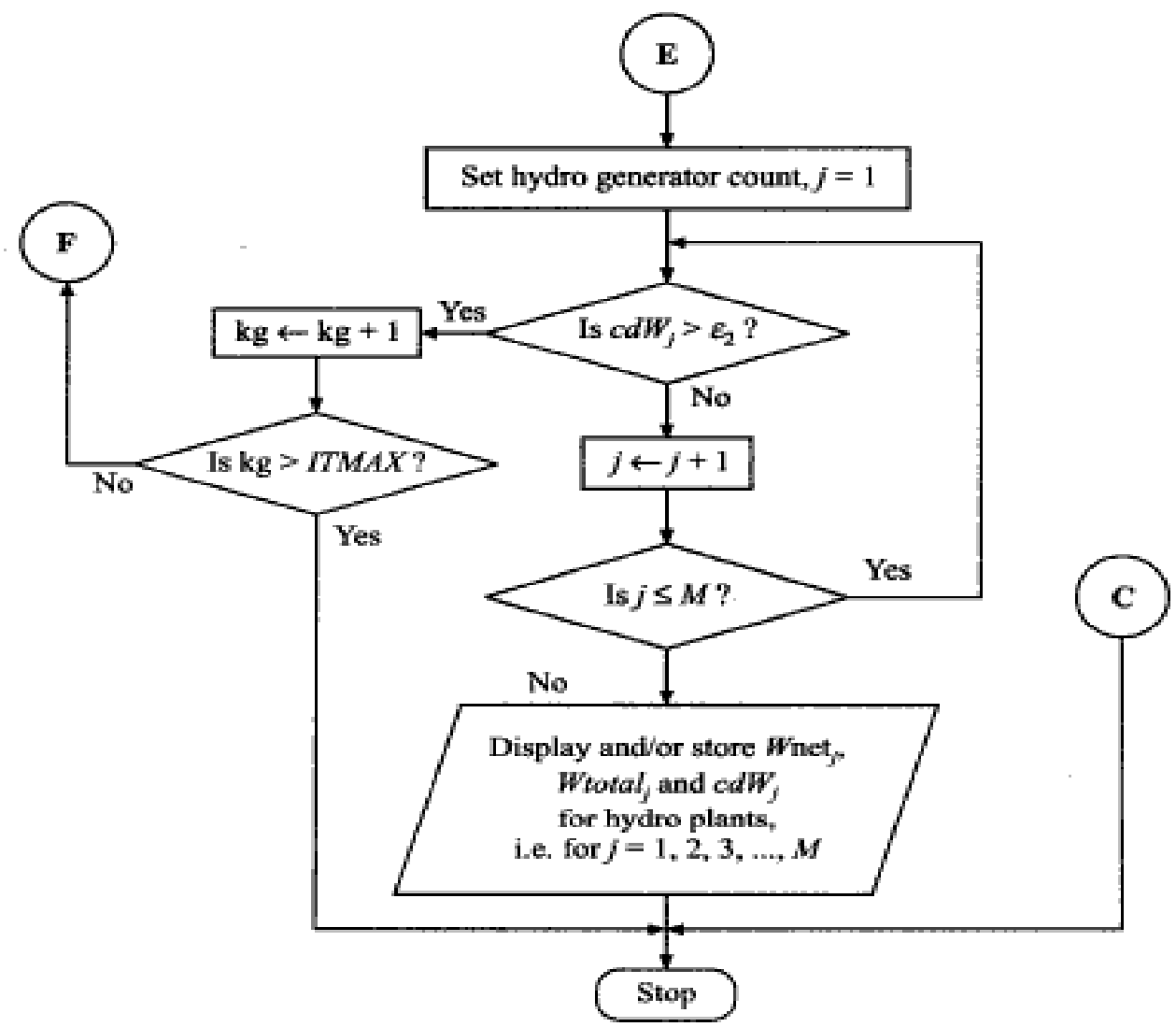

Flowchart to find short-term hydro-thermal schedule considering transmission line loss and involving a number of thermal and hydro generators using classical method.

Fig 2

\subsection{Genetic Algorithm}

A global optimization technique known as genetic algorithm has emerged as a candidate due to its flexibility and efficiency for many optimization applications. Genetic algorithm is a stochastic searching algorithm. It combines an artificial ,i.e., the Darwinian survival of the fittest principle of genetic operation, abstracted from nature to form a robust mechanism that is very effective at finding optimal solutions to complex real world problems. Evolutionary computing is an adaptive search technique based on the principles of genetics and natural selection. They operate on string structures. The string is a combination of binary digits representing a coding of the control parameters of a given problem. Many such string structures are considered simultaneously, with the most fit of these structures receiving exponentially increasing opportunities to pass on genetically important material to successive generation of string structures. In this way genetic algorithms search for many points is the search space at once, and yet continually narrow the focus of the search to the areas of the observed best performance. The basic elements of genetic algorithms are reproduction, crossover and mutation.

The first step is the coding of control variables as strings in binary numbers. In reproduction the individuals are selected based on their fitness values relative to those of population. In the crossover operation, the two individuals strings are selected at random from the mating pool and a crossover site is selected at random from the mating pool and a crossover site is selected at random along the string length. The binary digits are interchanged between two strings at crossover site. In Mutation, an occasional random alteration of a binary digit Is done. The above procedure to implement genetic algorithms is outlined below:

Algorithm: Genetic Algorithm

1. Code the problem variables into binary strings.

2. Randomly generate initial population strings. Tossing of a coin can be used.

3. Evaluate fitness values of population members.

4. Is solution available among the population?

If yes GOTO step 9.

5. Select highly fit strings as parents and produce off springs according to their fitness. 
6. Create new strings by mating current off spring. Apply crossover and mutation operators to introduce variations and form new strings.

7. New strings replace existing one.

8. GOTO step 4 ad repeat.

9. Stop.

Genetic algorithms are computerized search and optimization algorithms based on the principles of natural genetics and natural selection. Although genetic algorithm were first presented systematically by prof. John Holland of the university of Michigan, the basic ideas of analysis and design based on the concept of biological evolution can be found in the work of Goldberg.

Hydrothermal Scheduling Using Genetic Algorithm:-

1.Read data, namely cost coefficients, $a_{i}, b_{i}, c_{i}$, B-coefficients, $B_{i j}(i=1,2,3, \ldots ., N G ; j=1,2,3, \ldots \ldots . N G)$,number of steps for gamma correction (d), number of generations(z), step size $\alpha$, water availability throughout all intervals $\mathrm{q}, 1$ length of string, L population size, $\mathrm{p}_{\mathrm{c}}$ crossover probability, $\mathrm{p}_{\mathrm{m}}$ mutation probability, number of intervals $(\mathrm{t})$, $\lambda^{\min }$ and $\lambda^{\max }$ for each intervals etc.

2. Generate an array of random numbers. Generate the population $\lambda^{j}(j=1,2, \ldots . L)$ by flipping the coin for both intervals. The bit is set according to the coin flip as $b_{i j}=1$ if $p=1$ or $0<=p$ otherwise $b_{i j}=0$ where $p=0.5$.

3. Generate the initial population of gamma.

4. If number of iterations for gamma correction $>=d$ then GOTO step 24 else repeat step 4 to 23 .

5. If number of intervals $<=$ t repeat step 6 to 20 for each interval and increment interval counter each time else GOTO step 4.

6. Set the generation counter $\mathrm{k}=0, \mathrm{f}_{\max }=0$ and $\mathrm{f}_{\min }=1$.

7. If $\mathrm{k}>=\mathrm{z}$ GOTO step 5 else repeat step 7 to 20.

8. Increment generation counter $\mathrm{k}=\mathrm{k}+1$, and set population counter $\mathrm{j}=0$.

9. Increment the population counter $\mathrm{j}=\mathrm{j}+1$.

10.Decode the string using the equations $y_{j}=\sum_{i=1}^{l} 2^{-i} b_{i j}(\mathrm{j}=1,2, \ldots \ldots, \mathrm{L})$ and

$\lambda_{j}=\lambda_{j}^{\min }+\left(\lambda_{j}^{\max }-\lambda_{j}^{\min }\right) y_{j} /\left(2^{1}-1\right) \quad(\mathrm{j}=1,2, \ldots \ldots, \mathrm{L})$.

11. Use Gauss Elimination method to find $\mathrm{P}_{\mathrm{i}}^{\mathrm{j}}(\mathrm{i}=1,2, \ldots \ldots \mathrm{NG}$ including hydel and thermal generators).

12. Calculate the transmission loss.

13. Find out $\varepsilon^{\mathrm{j}}$.

14. Find out the fitness values from the fitness function $\mathrm{f}^{\mathrm{j}}=1 /\left(1+\alpha^{*} \varepsilon^{\mathrm{j}} / \mathrm{P}_{\mathrm{d}}\right)$. If $\left(\mathrm{f}^{\mathrm{j}}>\mathrm{f}^{\mathrm{max}}\right)$ then set $\mathrm{f}^{\max }=\mathrm{f}^{\mathrm{j}}$ and if $\left(\left(\mathrm{f}^{\mathrm{j}}<\mathrm{f}^{\mathrm{min}}\right)\right.$ then set $\mathrm{f}^{\mathrm{min}}=\mathrm{f}^{\mathrm{j}}$.

15. If $(\mathrm{j}<\mathrm{L})$ then GOTO step 9 and repeat.

16. Find population with maximum fitness and average fitness of the population.

17. Select the parents for crossover using stochastic remainder roulette wheel selection using the following algorithm:

\{ STOCHASTIC REMAINDER ROULETTE WHEEL SELECTION:

1. Input the fitness values of all individuals, $f_{i}(\mathrm{i}=1,2, \ldots \ldots, \mathrm{L})$, population size, $\mathrm{L}$.

2. Initialize the population counter, $i=0$ and initialize the selection counter, $j=0$.

3. Increment the selection counter, $\mathrm{j}=\mathrm{j}+1$.

4. Find $\left.\mathrm{y}=f_{j} \div\left[\left(\sum_{i=1}^{L} f_{i}\right) \div L\right)\right]$

5. Separate the integer part of $\mathrm{Y}$ real number, $\mathrm{I}=$ integer( $\mathrm{Y})$.

6. Separate the fractional part of $\mathrm{Y}, F_{j}=Y-I$.

7. If $(\mathrm{I}<0)$ then GOTO step 12.

8. Increment the population counter, $\mathrm{k}=\mathrm{k}+1$.

9. Decrease the integer part to zero, I=I-1.

10. $S E L_{k}=j$.

11. GOTO step 7 and repeat.

12. Check, if ( $\mathrm{j}>\mathrm{L})$ GOTO step 3 and repeat.

13. Reset the selection counter, $\mathrm{j}=0$.

14. If $(\mathrm{k}>\mathrm{L})$ GOTO step 19.

15. Increment the selection counter, $\mathrm{j}=\mathrm{j}+1$.

16. If $(j>L)$ then set $j=1$.

17. If $\left(F_{j}>0.0\right)$ then $\left\{\mathrm{W}=\mathrm{iflip}\left(F_{j}\right)\right\}$. If $(\mathrm{W}=1)$ then $\left\{\mathrm{k}=\mathrm{k}+1, S E L_{k}=j, F_{j}=F_{j}-1\right\}$ 
18. GOTO step 14 and repeat.

19. Stop.

\}

18. Perform single point crossover for the selected parents.

19. Perform the mutation.

20. Modify and create the new population of lambda for the next generation.

21. Check whether the total available water is enough for hydel generation in each interval.

22. Calculate the error in initially anticipated values of gammas' population.

23. Modify the values of gamma in gammas' population and GOTO step 4.

24. Stop.

\subsection{Differential Evolution (DE)}

DE or differential evolution belongs to the class of evolutionary algorithms that include evolution strategies (ES) and conventional genetic algorithms (GA). DE differs from the conventional genetic algorithms in its use of perturbing vectors, which are the difference between two randomly chosen vectors. DE is a scheme which it generates the trial vectors from a set of initial populations. In each step, DE mutates vectors by adding weighted random vectors differentials to them. If the fitness of the trial vector is better than that of the target vector, the trial vector replaces the target vector in the next generation.

DE offers several strategies for optimization. They are classified according to the following notations such as $\mathrm{DE} / x / y / z$, where $x$ refers to the method used for generating parent vector that will form the base for mutated vector, $y$ indicates the number of difference vector used in mutation process and $z$ is the crossover scheme used in the cross over operation to create the offspring population. The symbol $x$ can be 'rand' (randomly chosen vector) or 'best' (the best vector found so far). The symbol $y$ i.e. the number of difference vector, is normally set to be 1 or 2 . For cross over operation, a binomial (notation: 'bin') or exponential (notation: 'exp') operation is used. The version used here is the DE/rand/1/bin, which is described by the following steps:

\subsubsection{Initialization}

The optimization process in DE is carried with four basic operations: initialization, mutation, crossover and selection. The algorithm starts by creating a population vector $\mathrm{P}$ of size $\mathrm{N}_{\mathrm{p}}$ composed of individuals that evolve over $\mathrm{G}$ generation. Each individual $\mathrm{X}_{\mathrm{i}}$ is a vector that contains as many as elements as the problem decision variable. The population size $\mathrm{N}_{\mathrm{p}}$ is an algorithm control parameter selected by the user. Thus $\mathrm{P}^{(\mathrm{G})}=\left[{ }^{(\mathrm{G})} \mathrm{X}_{\mathrm{i}}, \ldots \ldots,{ }^{(\mathrm{G})} \mathrm{X}_{\mathrm{Np}}\right]$ ${ }^{(\mathrm{G})} \mathrm{X}_{\mathrm{i}}=\left[{ }^{(\mathrm{G})} \mathrm{X}_{\mathrm{i}}, \ldots \ldots,{ }^{(\mathrm{G})} \mathrm{X}_{\mathrm{D}, \mathrm{i}}\right]^{\mathrm{T}}, \mathrm{i}=1, \ldots \ldots, \mathrm{N}_{\mathrm{p}}$

The initial population is chosen randomly in order to cover the entire searching region uniformly. A uniform probability distribution for all random variables is assumed in the following as

${ }^{(0)} X_{j, I}={ }^{\min } X_{j}+\sigma_{j}\left({ }^{\max } X_{j}-{ }^{\min } X_{j}\right)$

Where $i=1, \ldots ., N_{p}$ and $j=1, \ldots \ldots, D$.

Here $D$ is the number of decision or control variable $s,{ }^{\min } X_{j}$ and ${ }^{\max } X_{j}$ are the lower and upper limits of the $\mathrm{j}$ the decision variables and $\sigma_{\mathrm{j}} \in[0,1]$ is a uniformly distributed random number generated a new for each value of $\mathrm{j}$. ${ }^{(0)} \mathrm{X}_{\mathrm{j}, \mathrm{I}}$ is the $\mathrm{j}^{\text {th }}$ parameter of the $\mathrm{i}^{\text {th }}$ individual of the initial population.

\subsubsection{Mutation operation}

Several strategies of mutation have been introduced in the literature of DE. The essential ingredient in the mutation operation is the vector difference. The mutation operation creates mutant vectors $\left(\mathrm{V}_{\mathrm{i}}\right)$ by perturbing a randomly selected vector $\left(X_{k}\right)$ with the difference of two other randomly selected vectors $\left(X_{t}\right.$ and $\left.X_{m}\right)$ according to

${ }^{(\mathrm{G})} \mathrm{V}_{\mathrm{i}}={ }^{(\mathrm{G})} \mathrm{X}_{\mathrm{k}}+\mathrm{f}_{\mathrm{m}}\left({ }^{(\mathrm{G})} \mathrm{X}_{\mathrm{l}}-{ }^{(\mathrm{G})} \mathrm{X}_{\mathrm{m}}\right)$

where $X_{k}, X_{1}$ and $X_{m}$ are randomly chosen vectors $\epsilon\left[1, \ldots . ., N_{p}\right]$ and $k \# 1 \# \mathrm{~m} \# \mathrm{i}$. In other words, the indices are mutually different including the running index $\mathrm{i}$. The mutation factor fm that lies within [0,2] is a user chosen parameter used to control the perturbation size in the mutation operator and to avoid search stagnation.

\subsubsection{Crossover operation}

In order to extend further diversity in the searching process, crossover operation is performed. The crossover operation generates trial vectors $\left(\mathrm{U}_{\mathrm{i}}\right)$ by mixing the parameter of the mutant vectors with the target vectors. For each mutant vector, in index $q \epsilon\left[1, \ldots \ldots, \mathrm{N}_{\mathrm{p}}\right]$ is chosen randomly using a uniform distribution and trial vectors are generated according to 


$$
\text { (G) } \begin{aligned}
\mathrm{U}_{\mathrm{j} . \mathrm{i}}={ }^{(\mathrm{G})} \mathrm{V}_{\mathrm{j}, \mathrm{i}} \text {, if } \eta_{\mathrm{j}} \leq \mathrm{C}_{\mathrm{r}} \text { or } \mathrm{j}=\mathrm{q} . \\
={ }^{(\mathrm{G})} \mathrm{X}_{\mathrm{j}, \mathrm{i}} \text {, otherwise. }
\end{aligned}
$$

Where $i=1, \ldots \ldots \ldots, N_{p}$ and $j=1, \ldots .$. D. $\eta_{j}$ is a uniformly distributed random number within $[0,1]$ generated anew for each value of $j$. The crossover factor $C_{R} \epsilon[0,1]$ is a user chosen parameter that controls the diversity of the population. ${ }^{(\mathrm{G})} \mathrm{X}_{\mathrm{j}, \mathrm{i}}{ }^{\left({ }^{(G)}\right)} \mathrm{V}_{\mathrm{j}, \mathrm{i}}$ and ${ }^{(\mathrm{G})} \mathrm{U}_{\mathrm{j}, \mathrm{i}}$ are the jth parameter of the ith target vector, mutant vector and trial vector at $\mathrm{G}$ generation, respectively.

\subsubsection{Selection operation}

Selection is the operation through which better offspring are generated. The evaluation (fitness) function of an offspring is compared to that of its parent. The parent is replaced by its offspring if the fitness of the offspring is better than that of its parent. While the parent is retained in the next generation if the fitness of the offspring is worse than that of its parent. Thus, if $f$ denotes the cost (fitness) function under optimization (minimization), then

$$
\begin{aligned}
{ }^{(\mathrm{G}+1)} \mathrm{X}_{\mathrm{i}} & ={ }^{(\mathrm{G})} \mathrm{U}_{\mathrm{i}}, \text { if } \mathrm{f}\left({ }^{(\mathrm{G})} \mathrm{U}_{\mathrm{i}}\right) \leq \mathrm{f}\left({ }^{(\mathrm{G})} \mathrm{X}_{\mathrm{i}}\right) \\
& { }^{(\mathrm{G})} \mathrm{X}_{\mathrm{i}}, \text { otherwise. }
\end{aligned}
$$

The optimization process is repeated for several generations. This allows individuals to improve their fitness while exploring the solution space for optimal value. The iterative process of mutation, crossover and selection on the population will continue until a user-specified stopping criterion, normally, the maximum number of generations allowed, is met. The other type of stopping criterion i.e. convergence to global optimum is possible if the global optimum of the problem is available. Keeping all these into consideration, the DE technique has been applied to solve the short-term combined economic emission scheduling problem of hydrothermal systems.

\section{Design Issues}

The following assumptions are taken into consideration while designing the problem

1.4 Hydro reservoir has constant head during operation.

4.2 The water spillage from the water reservoir has been neglected.

4.3 The operating schedule is for 24 hours while each interval is for one hour.

4.4 The beginning and ending storage volumes are specified.

\section{Testing}

In this section MATLAB program code is given of different procedures:

\subsection{Hydrothermal Scheduling using Genetic Algorithm}

\section{$\mathrm{f}=[.22 .515000 ; .002101000]$;}

\%the first row describes the water rate characteristics of the hydal plant.

$\%$ the second row describes the fuel cost characteristics of the thermal

$\%$ plant.

p1max $=700$;

$\mathrm{p} 1 \mathrm{~min}=50$

p2max $=700$;

$\mathrm{p} 2 \mathrm{~min}=100$

$\mathrm{b}=[4.45-.05 ;-.054 .5]^{*} 10^{\wedge}(-5) ; \% \mathrm{~B}-$ coefficient matrix

$1=22 ; \%$ String Length

pop $=20 ; \%$ pop $=$ number of population

$\mathrm{pc}=.8 ; \%$ Crossover probability

$\mathrm{pm}=.01 ; \%$ Mutation probability

$\mathrm{p}=.5$; \% Probability for creating random binary string

$\mathrm{pd} 1=350 ; \%$ Load demand during first interval

pd2=700;\%Load demand during second interval

$\%$ Limits of lamda during the two interval

lamdamin $1=11$;

lamdamax $1=11.5$;

lamdamin $2=12.9$;

lamdamax $2=13.3$;

$\%$ Maximum and minimum values of fitness function

$\operatorname{fmin} 1=1$;

$\operatorname{fmax} 1=0$;

$\operatorname{fmin} 2=1$; 


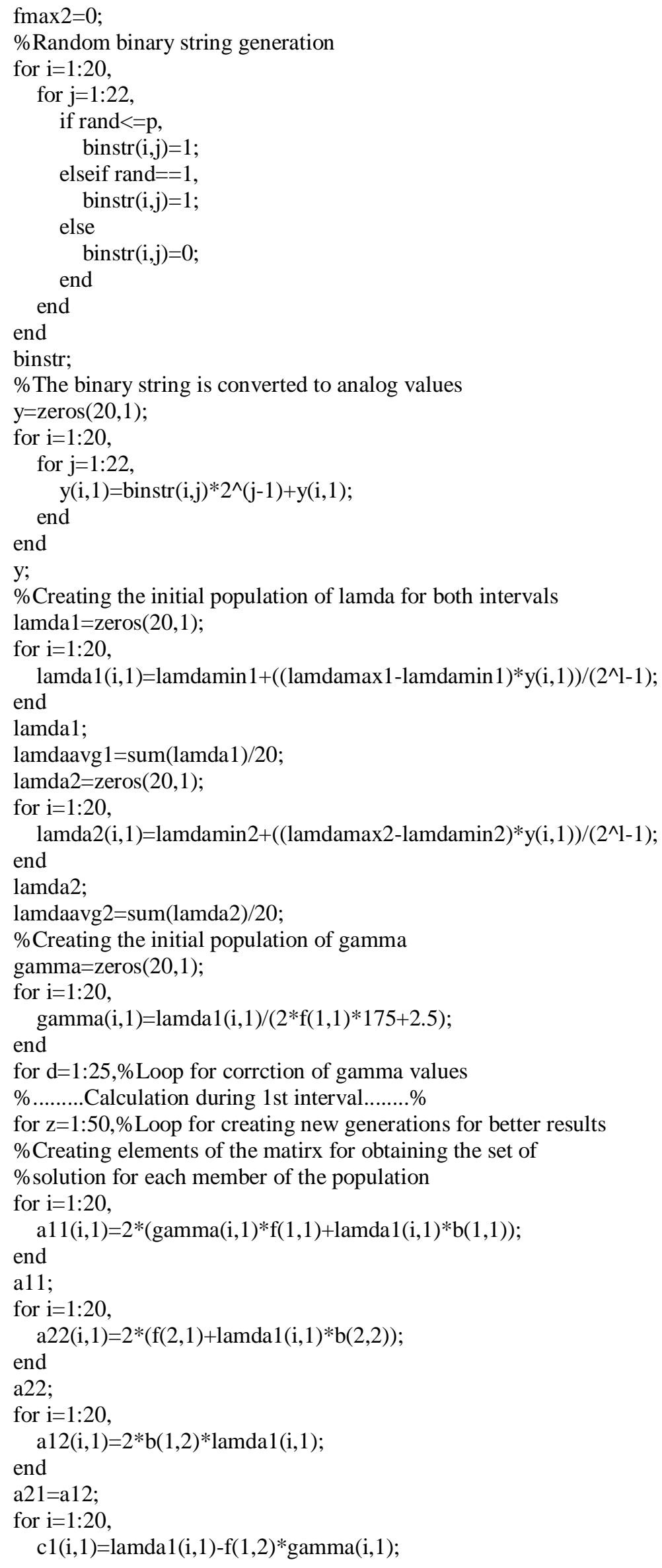




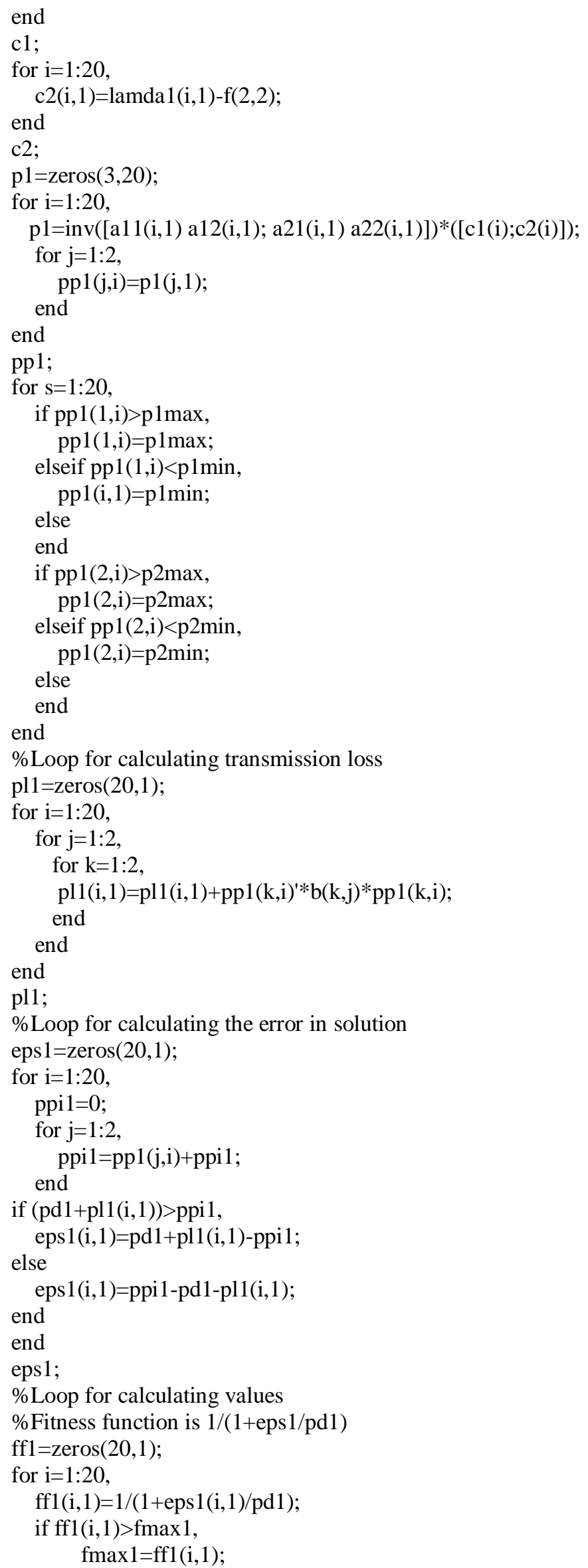




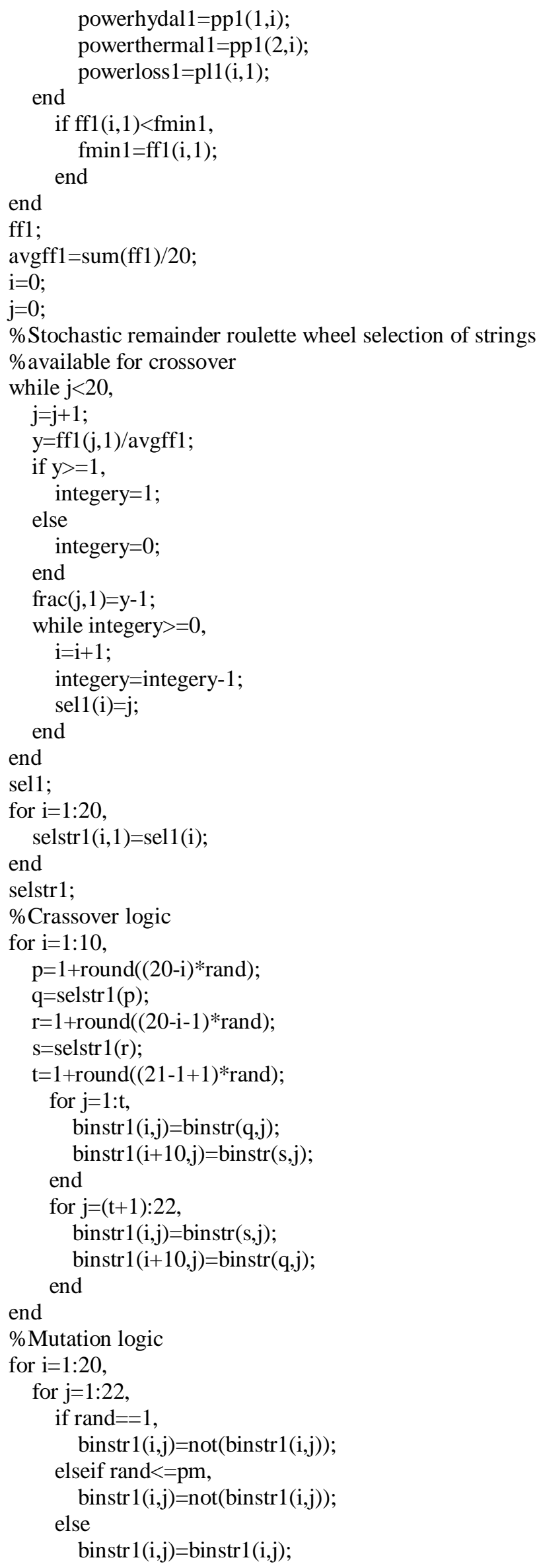




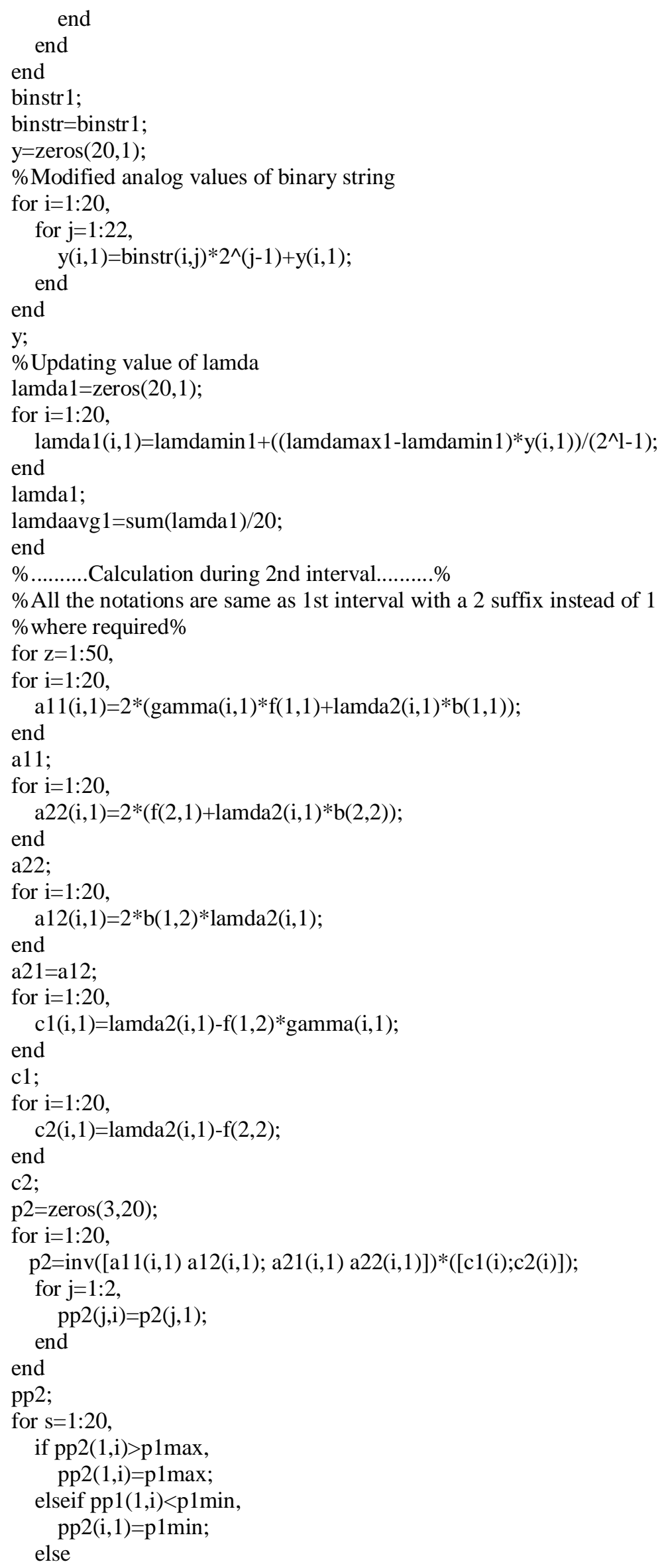




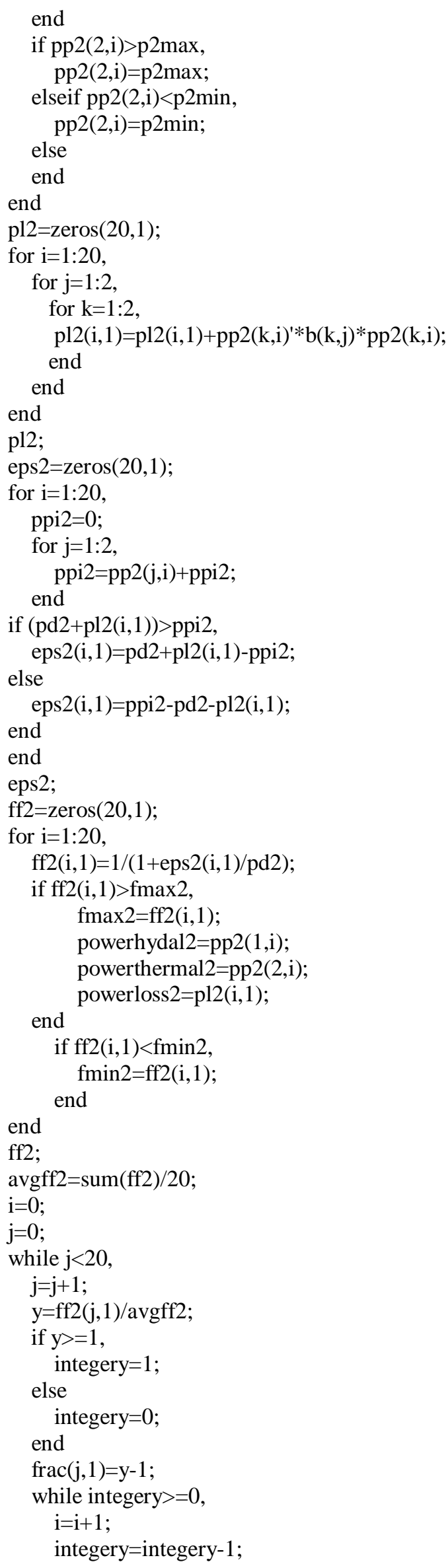




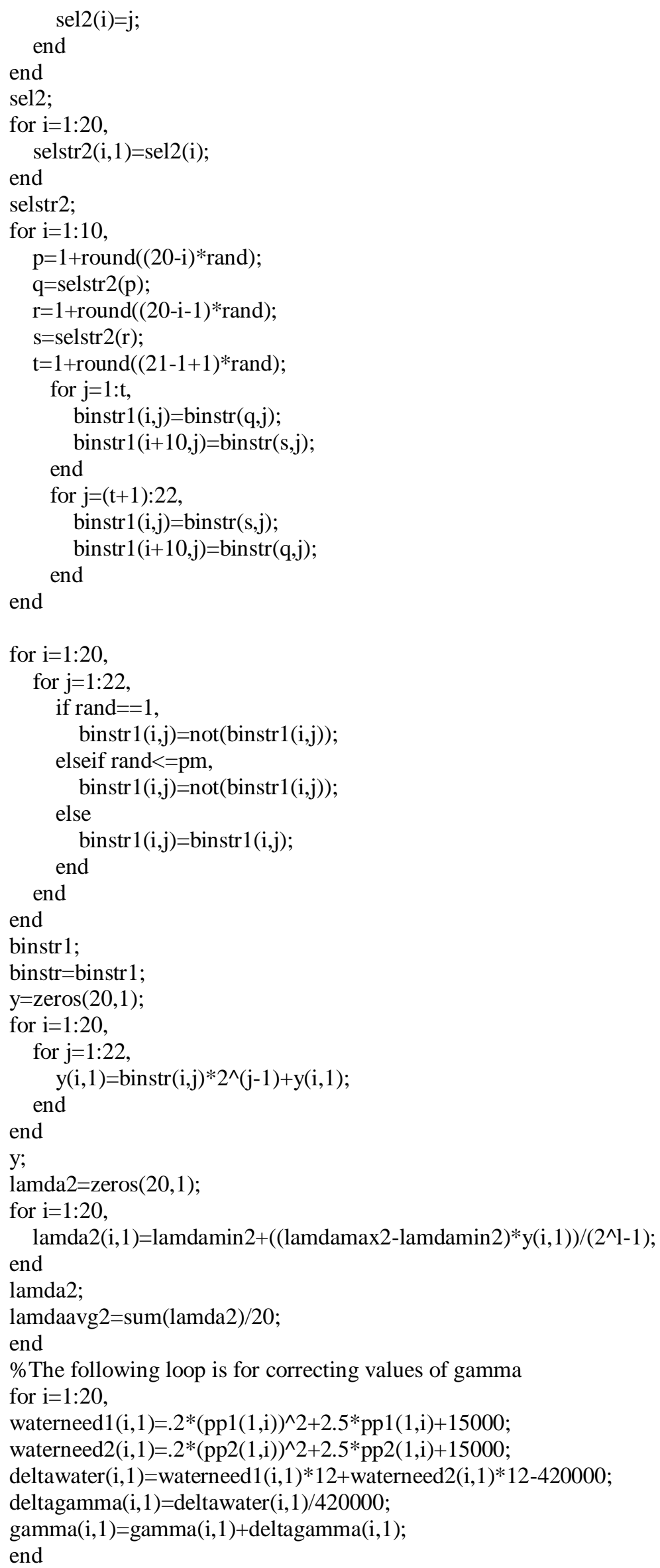


end

avgpowerhydal $1=0$;

avgpowerthermal $1=0$;

avgpowerhydal $2=0$;

avgpowerthermal2 $=0$;

$\%$ The following loop is for calculating average values of thermal and hydal

$\%$ generation during each interval

for $\mathrm{i}=1: 20$,

avgpowerhydal $1=$ avgpowerhydal $1+\mathrm{pp} 1(1, \mathrm{i}) / 20$;

avgpowerthermal $1=$ avgpowerthermal $1+\mathrm{pp} 1(2, \mathrm{i}) / 20$;

avgpowerhydal $2=$ avgpowerhydal $2+\mathrm{pp} 2(1, \mathrm{i}) / 20$;

avgpowerthermal $2=$ avgpowerthermal $2+\mathrm{pp} 2(2, \mathrm{i}) / 20$;

end

avgpowerhydal $1 \%$ Hydal generation during interval 1

avgpowerthermal $1 \%$ Thermal generation during interval 1

avgpowerhydal $2 \%$ Hydal generation during interval 2

avgpowerthermal $2 \%$ Thermal generation during interval 2

averageloss $1=\operatorname{sum}(\mathrm{pl} 1) / 20 \%$ Transmission loss during interval 1

averageloss $2=\operatorname{sum}(\mathrm{pl} 2) / 20 \%$ Transmission loss during interval 2

$\%$ Thermal generation cost during 1st interval

rupees $1=\mathrm{f}(2,1)^{*}$ avgpowerthermal $1^{\wedge} 2+\mathrm{f}(2,2) *$ avgpowerthermal $1+1000$

$\%$ Thermal of thermal generation during 2nd interval

rupees $2=\mathrm{f}(2,1)^{*}$ avgpowerthermal $2^{\wedge} 2+\mathrm{f}(2,2)^{*}$ avgpowerthermal $2+1000$

\subsection{Hydrothermal Scheduling using Differential Evolution}

\section{$\mathrm{f}=[.22 .515000 ; .002101000]$}

$\%$ the first row describes the water rate characteristics of the hydal plant.

$\%$ the second row describes the fuel cost characteristics of the thermal

$\%$ plant.

$\mathrm{p} 1 \max =700$

$\mathrm{p} 1 \mathrm{~min}=50$

$\mathrm{p} 2 \max =700$

$\mathrm{p} 2 \mathrm{~min}=100$

$\mathrm{b}=[4.45-.05 ;-.054 .5]^{*} 10^{\wedge}(-5) ; \% \mathrm{~B}$-coefficient matrix

$1=22 \%$ String Length

pop $=20 \%$ number of population

$\mathrm{pc}=.8 \%$ Crossover probability

$\mathrm{pm}=.01 \%$ Mutation probability

$\mathrm{p}=.5 \%$ Probability for creating random binary string

$\mathrm{pd} 2=700 \%$ Load demand during second interval

pd $1=350 \%$ Load demand during first interval

$\%$ Limits of lamda during the two interval

lamdamin $2=12.9$

lamdamax $2=13.3$

lamdamin $1=11$.

lamdamax $1=11.5$

$\%$ Maximum and minimum values of fitness function

fmin $1=1$

$\operatorname{fmax} 1=0$

fmin $2=1$

fmax $2=0$

$\%$ Random binary string generation

for $\mathrm{i}=1: 20$,

for $\mathrm{j}=1: 22$,

if rand $<=\mathrm{p}$,

$\operatorname{binstr}(\mathrm{i}, \mathrm{j})=1$;

elseif rand $==1$,

$\operatorname{binstr}(i, j)=1$;

else 


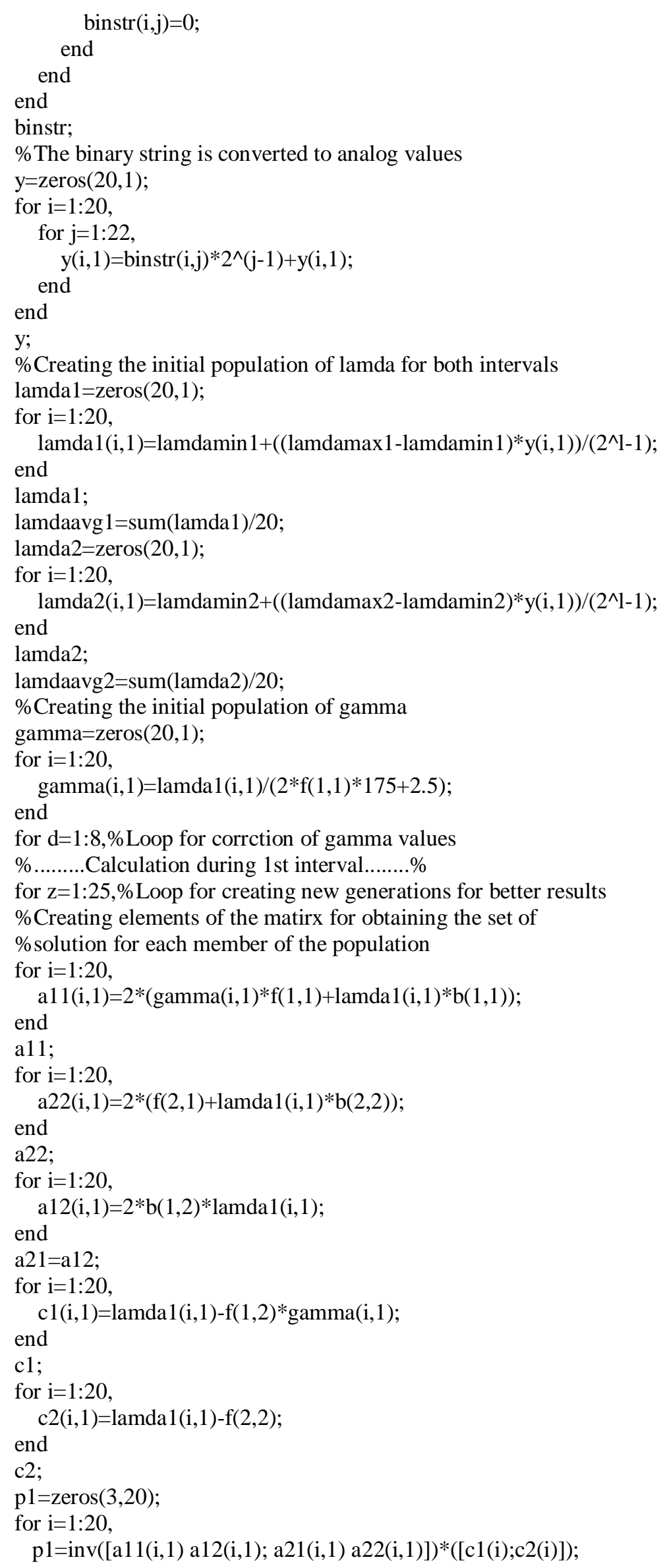




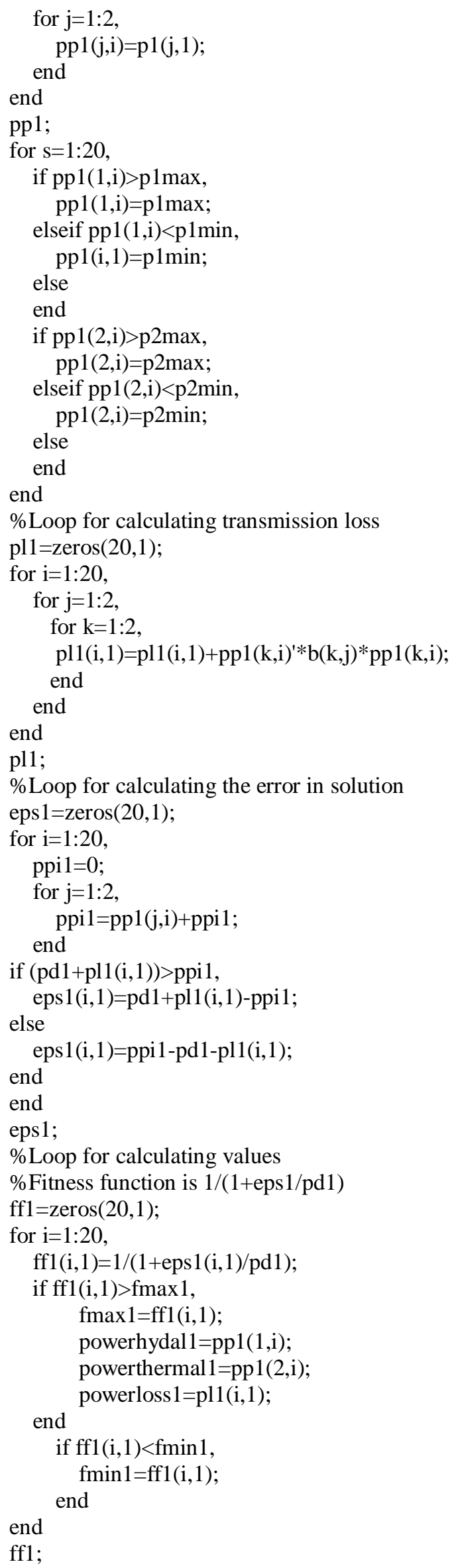

ff1; 
$\%$ comparing the fitness functiion between two succesive values and updating $\%$ the best one for 1 st interval\%

for $\mathrm{i}=1: 20$;

$$
\operatorname{pp} 11(1, \mathrm{i})=\operatorname{pp} 1(1, \mathrm{i}) \text {; }
$$

$\operatorname{pp} 11(2, \mathrm{i})=\operatorname{pp} 1(2, \mathrm{i})$;

$\operatorname{pl11}(\mathrm{i}, 1)=\mathrm{pl}(\mathrm{i}, 1)$;

eps11(i,1)=eps1(i,1);

ff11(i,1)=ff1(i,1);

for $\mathrm{j}=1: 22$;

binstr $1(i, j)=\operatorname{binstr}(i, j)$;

end

end

for $\mathrm{i}=1: 20$;

if ff1(i,1)<ff11(i,1),

ff1 $(i, 1)=f f 11(i, 1)$;

for $\mathrm{j}=1: 22$;

$\operatorname{binstr}(\mathrm{i}, \mathrm{j})=\operatorname{binstr} 1(\mathrm{i}, \mathrm{j})$;

end

$\operatorname{pp} 1(1, \mathrm{i})=\operatorname{pp} 11(1, \mathrm{i})$;

$\operatorname{pp} 1(2, \mathrm{i})=\operatorname{pp} 11(2, \mathrm{i})$;

pl1(i,1)=pl11(i,1);

eps1(i,1)=eps11(i,1);

else

end

end

$\operatorname{avgff} 1=\operatorname{sum}(\mathrm{ff} 1) / 20$;

$\mathrm{i}=0$;

$\mathrm{j}=0$;

$\%$ Stochastic remainder roulette wheel selection of strings

$\%$ available for crossover

while $\mathrm{j}<20$,

$\mathrm{j}=\mathrm{j}+1$;

$\mathrm{y}=\mathrm{ff} 1(\mathrm{j}, 1) / \operatorname{avgff} 1$;

if $\mathrm{y}>=1$,

else

integery $=1$;

integery $=0$;

end

$\operatorname{frac}(\mathrm{j}, 1)=\mathrm{y}-1$;

while integery $>=0$,

$\mathrm{i}=\mathrm{i}+1$;

integery=integery-1;

$\operatorname{sel1}(\mathrm{i})=\mathrm{j}$;

end

end

sel1;

for $\mathrm{i}=1: 20$,

selstr1 $(i, 1)=\operatorname{sel} 1(i)$;

end

selstr1;

$\%$ Crassover logic

for $\mathrm{i}=1: 10$,

$\mathrm{p}=1+\operatorname{round}((20-\mathrm{i}) *$ rand $)$;

$\mathrm{q}=\operatorname{sel} \operatorname{str} 1(\mathrm{p})$;

$\mathrm{r}=1+\operatorname{round}((20-\mathrm{i}-1) *$ rand $)$;

$\mathrm{s}=\operatorname{selstr} 1(\mathrm{r})$;

$\mathrm{t}=1+\operatorname{round}((21-1+1) *$ rand $)$;

for $\mathrm{j}=1: \mathrm{t}$,

$\operatorname{binstr} 1(i, j)=\operatorname{binstr}(q, j)$; 


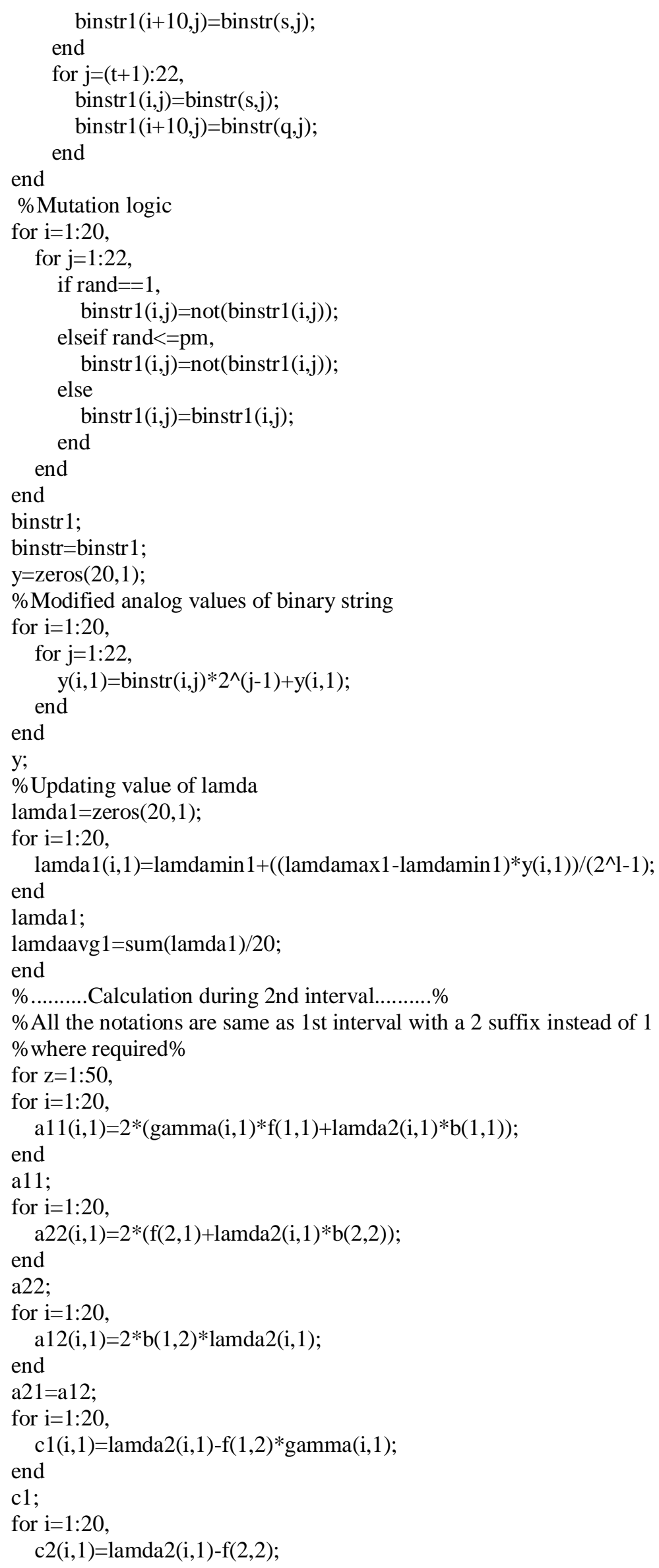




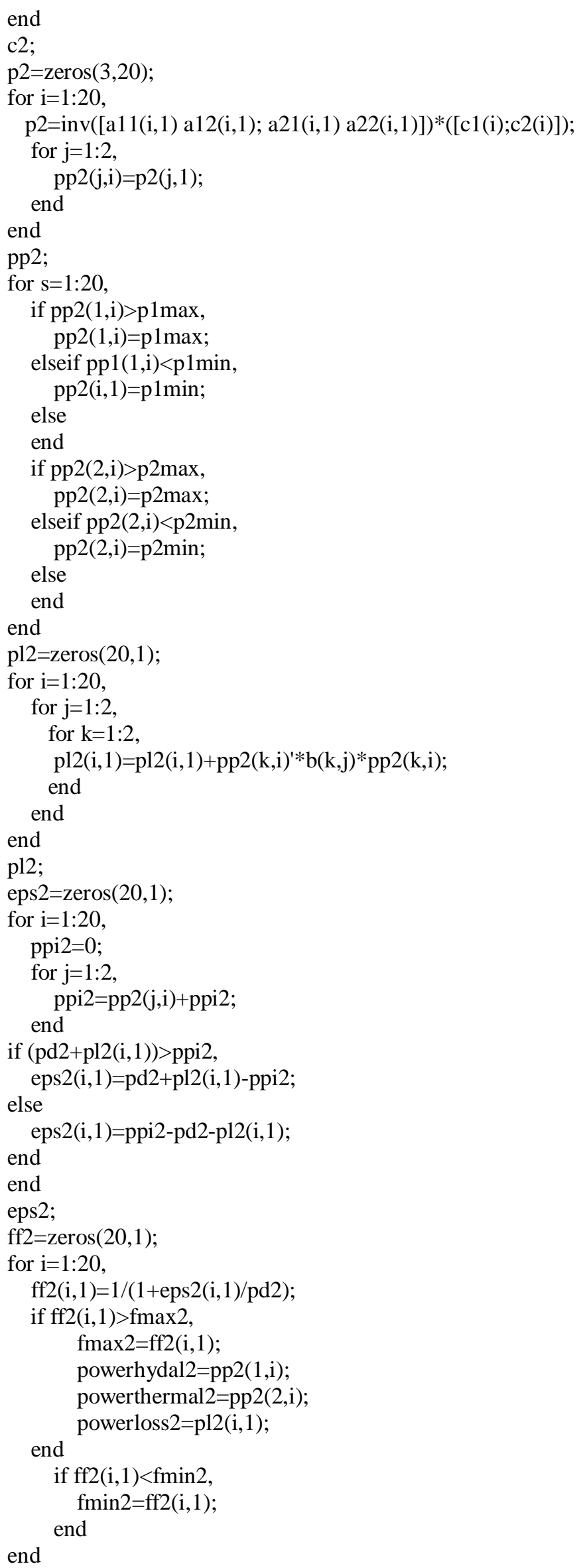


ff2;

\%comparing the fitness functiion between two succesive values and updating $\%$ the best one for 2 nd interval\%

for $\mathrm{i}=1: 20$;

$\operatorname{pp} 12(1, \mathrm{i})=\mathrm{pp} 2(1, \mathrm{i})$;

$\operatorname{pp} 12(2, \mathrm{i})=\mathrm{pp} 2(2, \mathrm{i})$;

pl12(i,1)=pl2(i,1);

eps12(i,1)=eps2(i,1);

ff12(i,1)=ff2(i,1);

for $\mathrm{j}=1: 22$;

$\operatorname{binstr} 1(\mathrm{i}, \mathrm{j})=\operatorname{binstr}(\mathrm{i}, \mathrm{j})$;

end

end

for $\mathrm{i}=1: 20$;

if ff2(i,1)<ff12(i,1),

ff2 $(\mathrm{i}, 1)=\mathrm{ff} 12(\mathrm{i}, 1)$;

for $j=1: 22$;

$\operatorname{binstr}(\mathrm{i}, \mathrm{j})=\operatorname{binstr}(\mathrm{i}, \mathrm{j})$;

end

$\mathrm{pp} 2(1, \mathrm{i})=\mathrm{pp} 12(1, \mathrm{i})$;

$\operatorname{pp} 2(2, \mathbf{i})=\operatorname{pp} 12(2, \mathbf{i})$

pl2(i,1)=pl12(i,1);

eps2(i,1)=eps12(i,1);

else

end

end

avgff $2=\operatorname{sum}(\mathrm{ff} 2) / 20$;

$\mathrm{i}=0$;

$\mathrm{j}=0$;

while $\mathrm{j}<20$,

$\mathrm{j}=\mathrm{j}+1$;

$y=f f 2(j, 1) / \operatorname{avgff2} ;$

if $y>=1$,

else

integery $=1$;

integery $=0$;

end

frac $(\mathrm{j}, 1)=\mathrm{y}-1$;

while integery $>=0$,

$\mathrm{i}=\mathrm{i}+1$;

integery=integery- 1 ;

$\operatorname{sel} 2(i)=j$;

end

end

sel2;

for $\mathrm{i}=1: 20$,

selstr2(i,1)=sel2(i);

end

selstr2;

for $\mathrm{i}=1: 10$,

$\mathrm{p}=1+\operatorname{round}((20-\mathrm{i}) *$ rand $)$;

$\mathrm{q}=\operatorname{selstr} 2(\mathrm{p})$;

$\mathrm{r}=1+\operatorname{round}((20-\mathrm{i}-1) *$ rand $)$;

$\mathrm{s}=$ selstr2(r);

$\mathrm{t}=1+\operatorname{round}((21-1+1) * \mathrm{rand})$;

for $\mathrm{j}=1: \mathrm{t}$,

$\operatorname{binstr} 1(\mathrm{i}, \mathrm{j})=\operatorname{binstr}(\mathrm{q}, \mathrm{j})$;

$\operatorname{binstr} 1(i+10, j)=\operatorname{binstr}(s, j)$;

end 


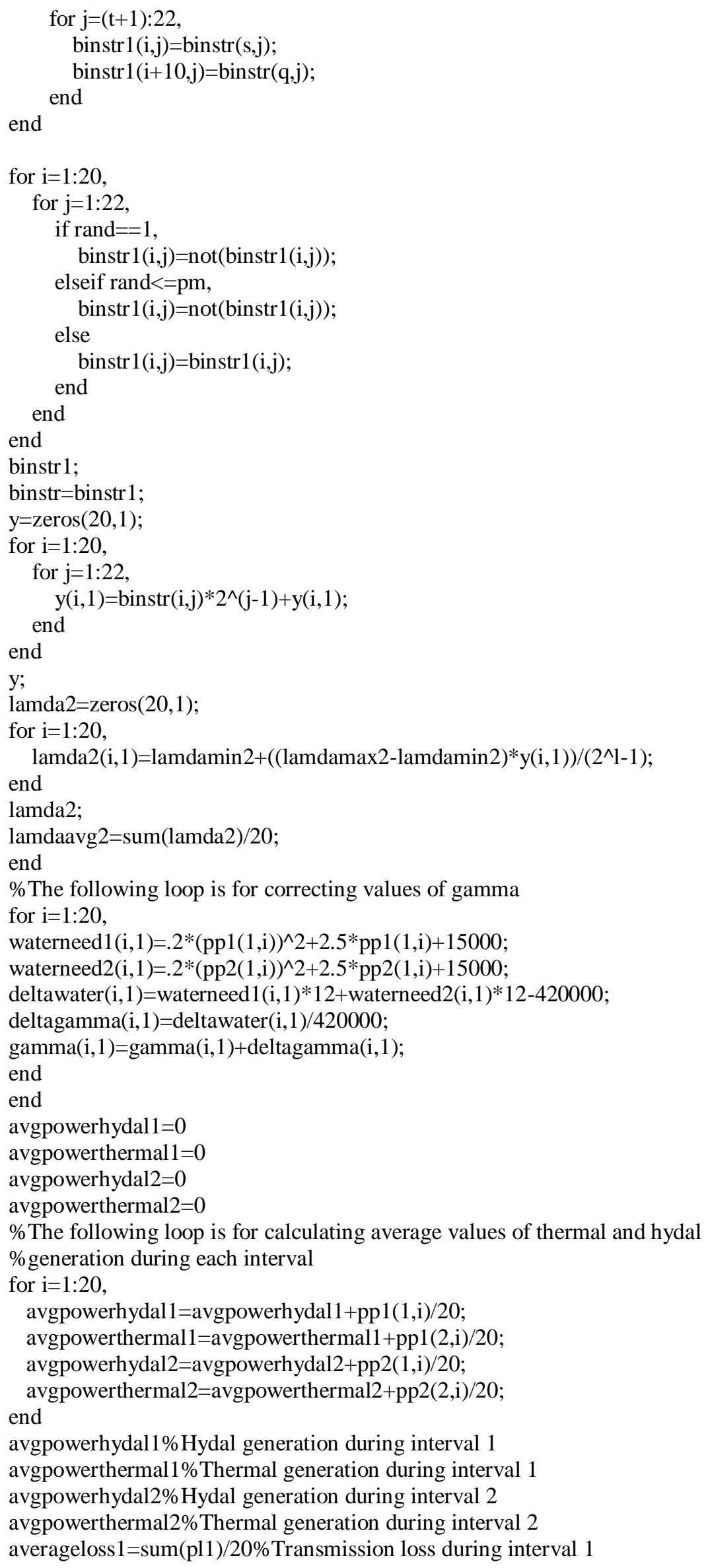


averageloss $2=\operatorname{sum}(\mathrm{pl} 2) / 20 \%$ Transmission loss during interval 2

$\%$ Thermal generation cost during 1 st interval

rupees $1=\mathrm{f}(2,1) *$ avgpowerthermal $1 \wedge 2+\mathrm{f}(2,2) *$ avgpowerthermal $1+1000$

$\%$ Thermal of thermal generation during 2 nd interval

rupees $2=\mathrm{f}(2,1) *$ avgpowerthermal $2^{\wedge} 2+\mathrm{f}(2,2) *$ avgpowerthermal $2+1000$

\section{Measurements, Results and Discussions \\ 1.7 Result of Hydrothermal Scheduling using Classical Method}

avgpowerhydal $1=97.0568$

avgpowerthermal $1=256.2839$

avgpowerhydal $2=113.7627$

avgpowerthermal $2=603.1106$

averageloss $1=3.3508$

averageloss $2=16.8773$

rupees $1=3.6942 \mathrm{e}+003$

rupees $2=7.758 \mathrm{e}+003$

\subsection{Result of Hydrothermal Scheduling using Genetic Algorithm}

avgpowerhydal $1=97.0613$

avgpowerthermal $1=256.1341$

avgpowerhydal $2=113.7632$

avgpowerthermal $2=603.0219$

averageloss $1=3.3339$

averageloss $2=16.7512$

rupees $1=3.6926 \mathrm{e}+003$

rupees $2=7.7575 \mathrm{e}+003$

\subsection{Result of Hydrothermal Scheduling using Differential Evolution}

avgpowerhydal1 $=97.2076$

avgpowerthermal1 $=255.0306$

avgpowerhydal $2=113.9729$

avgpowerthermal $2=602.6239$

averageloss $1=3.3103$

averageloss $2=16.7320$

rupees $1=3.6804 \mathrm{e}+003$

rupees $2=7.7525 \mathrm{e}+003$

\section{Discussions}

From the results obtained above a comparison can be drawn among the three methods (Classical Method, Genetic Algorithm and the Differential Evolutionary Algorithm) with respect to their effectivity in solving the Short Term Fixed Head Hydrothermal Scheduling Problem considering Transmission Line Loss.

It can be observed from the above results that in the Differential Evolutionary Algorithm the scheduled generation for the hydel power plant in maximum for each interval and from the classical method solution we can observe that the scheduled generation for the hydel power plant in minimum for each interval among the three methods. Solution of Genetic Algorithm gives the scheduled hydel generation values in between the above two methods.

As the running cost of hydel plant is very low compared to the thermal power plant so it can be said that solving by Differential Evolutionary Algorithm we get the best solution of the Short Term Fixed Head Hydrothermal Scheduling Problem considering Transmission Line Loss followed by Genetic Algorithm and Classical Method.

Consequently the overall running cost per hour of the hydrothermal system is minimum for the solution of the Differential Evolutionary Algorithm followed by the solutions of the Genetic Algorithm and Classical Method which is in accordance with the above obtained results. 
The following table shows the comparison

\begin{tabular}{|c|c|c|c|c|c|c|}
\hline $\begin{array}{l}\text { SOLUTION } \\
\text { METHOD }\end{array}$ & $\begin{array}{l}\text { HYDEL } \\
\text { GENERATIO } \\
\mathrm{N} \quad \text { IN } \\
\text { INTERVAL } 1 \\
\text { IN MW }\end{array}$ & \begin{tabular}{l}
\multicolumn{2}{l}{ THERMAL } \\
GENERATIO \\
$\mathrm{N} \quad$ IN \\
INTERVAL 1 \\
IN MW
\end{tabular} & $\begin{array}{lr}\text { COST OF } \\
\text { THERMAL } \\
\text { GENERATIO } \\
\text { N IN } \\
\text { INTERVAL } \\
\text { IN RS/HR }\end{array}$ & $\begin{array}{l}\text { HYDEL } \\
\text { GENERATIO } \\
\text { N } \\
\text { INTERVAL } 2 \\
\text { IN MW }\end{array}$ & \begin{tabular}{l}
\multicolumn{2}{l}{ THERMAL } \\
GENERATIO \\
$\mathrm{N} \quad$ IN \\
INTERVAL 2 \\
IN MW
\end{tabular} & $\begin{array}{lr}\text { COST } & \text { OF } \\
\text { THERMAL } \\
\text { GENERATIO } \\
\text { N } \\
\text { INTERVAL } \\
\text { IN RS/HR }\end{array}$ \\
\hline $\begin{array}{l}\text { Classical } \\
\text { Method }\end{array}$ & 97.0568 & 256.2839 & 3694.20 & 113.7627 & 603.1106 & 7758 \\
\hline $\begin{array}{l}\text { Genetic } \\
\text { Algorithm }\end{array}$ & 97.0613 & 256.1341 & 3692.60 & 113.7632 & 603.0219 & 7757.70 \\
\hline $\begin{array}{l}\text { Differential } \\
\text { Evolutionar } \\
\text { y Algorithm }\end{array}$ & 97.2076 & 255.0306 & 3680.40 & 113.9729 & 602.6239 & 7752.50 \\
\hline
\end{tabular}

\section{Table 1}

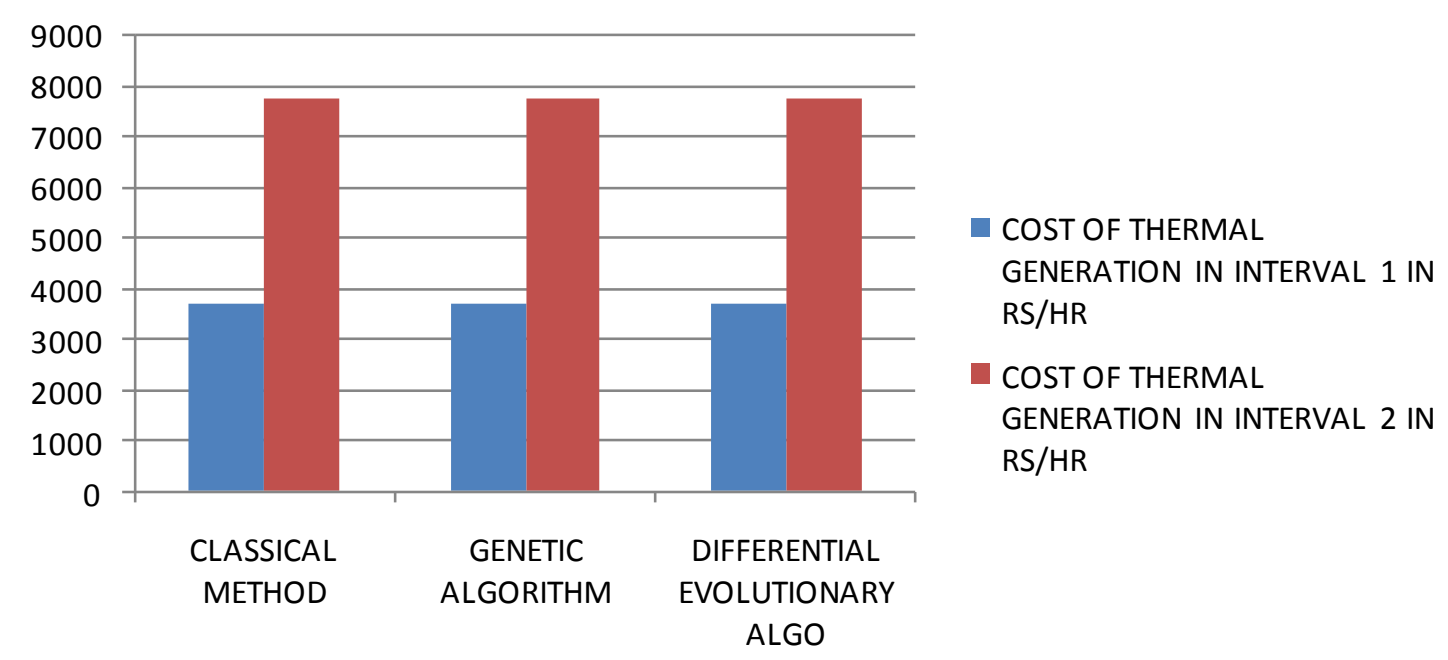

Fig 3

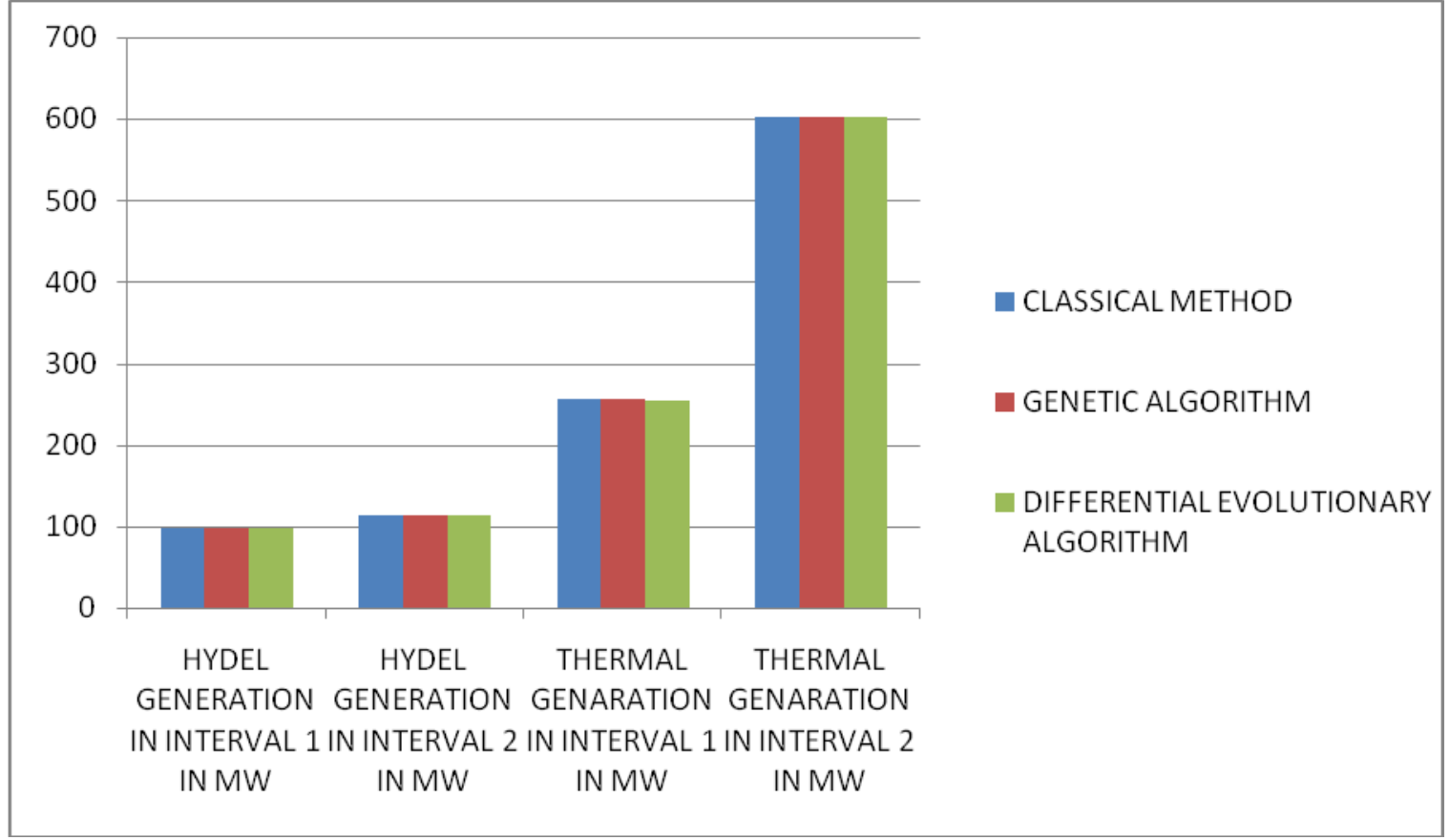

Fig 4 


\section{Conclusion}

In the concluding remarks it can be stated that the result obtained by Differential Evolutionary Algorithm is the best followed by the solutions obtained by the Genetic Algorithm and Classical Method.

So Fixed Head Short Term Hydrothermal Scheduling considering Transmission Loss can be done by Differential Evolutionary Algorithm in order minimize the generation cost of thermal power plant and to make use of limited water resource optimally to meet the load demand in each interval in the network.

On doing this program some assumptions were taken into consideration such as water head of hydro reservoir to be constant during operation, water spillage from the water reservoir has been neglected, the operating schedule is for 24 hours while each interval is for one hour, beginning and ending water storage volumes are specified.

[1] Learning programming using MATLAB Khalid Sayood

[2] Electrical Power Systems Wadhwa, C.L.2009

[3] Power System Analysis: Operation And Control 3Rd Ed. Chakrabarti \& Halder

[4] Power System Analysis Operation And Control 2ed Chakrabarti/halder

[5] Power System Optimization D. P. Kothari, J. S. Dhillon,2004,572 pages

[6] Optimization of Power System Operation Jizhong Zhu,2009,603 pages

[7] Power System Engineering 2e Kothari \& Nagrath,2008,1050 pages

[8] ABA Journal - Aug 1956 Vol. 42,100 pages,Magazine

[9] A genetic algorithm modelling framework and solution technique for short term optimal hydrothermal scheduling,SO Orero... Power Systems, IEEE Transactions on, 2002 - ieexplore.ieee.org

[10] Short-term hydrothermal scheduling part. I. Simulated annealing approach,KP Wong... - Generation, Transmission and ..., 2002 ieeexplore.ieee.org

[11] Nonlinear approximation method in Lagrangian relaxation-based algorithms for hydrothermal Scheduling [PDF] from uconn.eduX Guan, PB Luh... - Power Systems, IEEE Transactions ..., 2002 - ieeexplore.ieee.org

[12] Fast evolutionary programming techniques for short-term hydrothermal scheduling N Sinha, R Chakrabarti... - Electric Power Systems ..., 2003 - Elsevier

[13] Optimum short-term hydrothermal scheduling with spinning reserve through network flows,FJ Heredia... - Power Systems, IEEE Transactions ..., 2002 - ieeexplore.ieee.org

[14] An efficient hydrothermal scheduling algorithm MF Carvalho, S Soares - Power Systems, IEEE Transactions ..., 2007 ieeexplore.ieee.org

[15] A. Cohen and V. Sherkat, "Optimization-Based Methods for Operations Scheduling," Proceedings of IEEE, Vol. 75, No. 12, 1987, pp. 1574-1591.

[16] Differential evolution-a simple and efficient heuristic for global optimization over continuous space R Storn... - Journal of global optimization, 1997 - Springer 